\title{
Uma fascinante memória histórica
}

\author{
Ana Isabel Vasconcelos
}

\author{
Norberto Ávila, Do desencanto à revolta / Os deserdados \\ da pátria, Lisboa, Novo lmbondeiro, 2003, 172 pp.
}

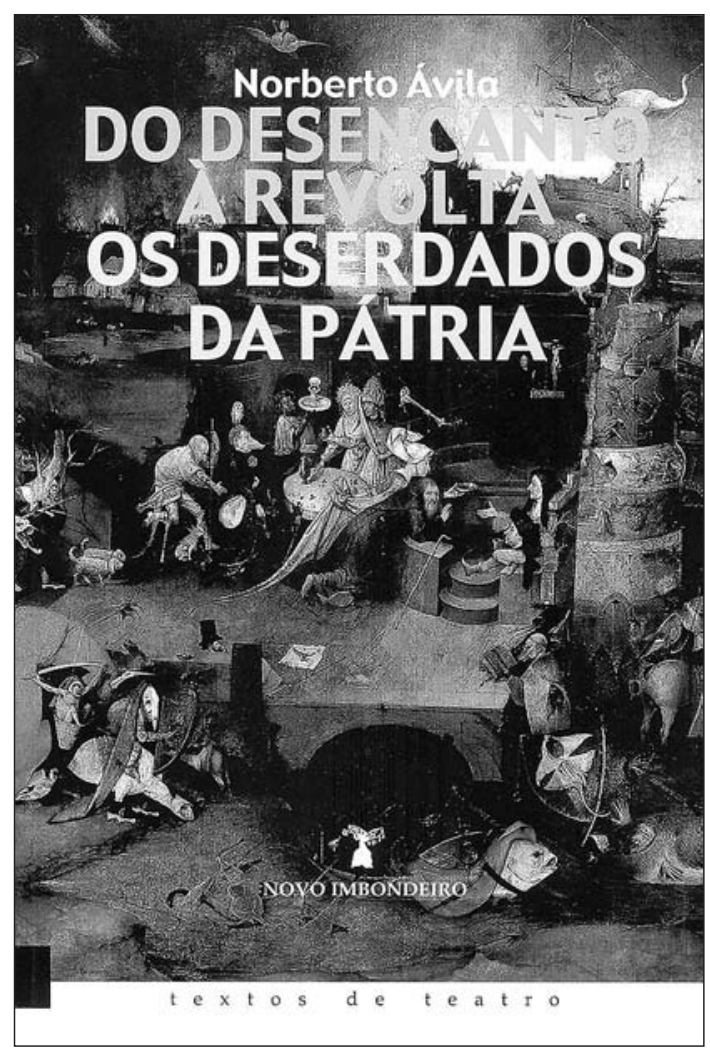

A relação que o leitor comum estabelece com uma obra começa naturalmente pela observação da capa que, no caso do mais recente livro da autoria do dramaturgo Norberto Ávila, tem, como imagem de fundo, o famoso e estranhíssimo quadro de Hieronymus Bosch, intitulado As tentações de Santo Antão, exposto no Museu Nacional de Arte Antiga, em Lisboa.

É indiciadoramente envolvido por este tríptico que se encontra o díptico - objecto desta recensão -, obra composta por duas "peças de teatro", que, mais do que se complementarem, se completam. Como se explica numa breve introdução, embora permanecessem inéditos, estes textos tinham sido escritos havia alguns anos e, na versão primeira, constituiam um só. Devido à sua dimensão, decidiu o autor dividi-lo em dois, autónomos mas com uma estreita relação cronológica e factual, intitulando-os "Do desencanto à revolta" e "Os deserdados da pátria", respectivamente.

São então dados à estampa, num só volume, dois dramas que poderemos considerar "históricos". Trata-se de um género resultante da confluência de duas disciplinas - a
História e a Literatura - que, à partida, se situam em esferas, se não opostas, pelo menos de difícil articulação. A própria designação - drama histórico - denota alguma

conflitualidade na relação dos seus termos que, apesar de associados, nos remetem para contextos referenciais diferentes, ou seja, o "mundo das verdades históricas" que adjectiva, compromete e restringe determinado universo de produção ficcional.

A utilização do facto histórico na criação dramática implica que se particularize e se restrinja o conteúdo de uma forma de produção que é, na sua essência, tendencialmente universal. Encontramo-nos, assim, perante um possivel conflito criado pelo facto de se pretender encaixar a particularidade, de determinado momento ou figura históricos, na universalidade, que já Aristóteles defendia como inerente aos assuntos ficcionais. Este constrangimento não implica, contudo, que o drama tenha que perder potencialidades estéticas. Cabe ao criador dramático saber trabalhar os elementos que Ihe chegam do passado, tornando-os universalmente aplicáveis, logo mais condizentes com a sua utilização numa estrutura ficcional. Com referentes históricos explícitos, não se espera que 0 autor adultere os dados tidos como prováveis, mas que os trabalhe por forma a destacar a "exemplaridade" dos factos utilizados. Este difícil entrelaçar da História na Fiç̧ão é aqui tecido por Norberto Ávila de uma forma magistral.

Entramos no primeiro texto a bordo da nau "São Jorge", propriedade do armador Baltasar de Montemor, que se encontra ancorada no porto de Antuérpia, pronta a rumar a Portugal. Bernardim de Montemor despede-se de Damião de Góis e regressa a Lisboa, onde Ihe fora prometido o cargo de Reitor do Colégio Paulo III. A intriga centra-se fundamentalmente nas "nefastas" influências do luteranismo nos humanistas portugueses, facto vigiado e perseguido pelos Jesuitas.

Já percebemos que a acção deste díptico tem como painel de fundo a época de D. João III, mais concretamente o período de 1540 a 1546, e que se passa entre Antuérpia e Lisboa. 0 ponto de vista predominante é o dos "estrangeirados", ou seja, dos que vivem, ainda que temporariamente, longe da Pátria, tendo a sua formação académica sido completada em grandes universidades europeias. A política até então seguida pelo monarca fora a de apoiar este tipo de formação, aproveitando então o contributo apreciável que o regresso destes humanistas daria certamente à sociedade portuguesa.

No momento em que Bernardim de Montemor regressa a Portugal, depois de concluídos os estudos no Colégio de 
Santa Bárbara, em Paris, já sopram ventos adversos de mudança. 0 texto preocupa-se em revelar esse processo, fornecendo, de uma forma extraordinariamente didáctica, até porque muito clara, elementos contextuais históricos que vão explicando a evolução dos acontecimentos.

A personagem emblemática desta obra é Damião de Góis, uma plasmação literária da figura histórica que todos, melhor ou pior, conhecemos. Neste universo construido funciona como amigo intimo da personagem que podemos considerar como a principal, Bernardim de Montemor, estabelecendo com este uma permanente interacção. Apesar de nem sempre presente em cena, Damião de Góis é a referência, em termos intelectuais, embora o símbolo de resistência e de defesa do valor e do princípio de liberdade seja Bernardim. É através desta personagem que vivemos o drama, ou melhor, a tragédia provocada pela mentalidade preconceituosa dos jesuitas, que, sabendo do seu relacionamento com o futuro cronista e com as doutrinas de Erasmo e de Lutero, logo o afastam do cargo que lhe tinha sido prometido, colocando nesse lugar o Padre Simão Rodrigues, um jesuita que a História indica como tendo denunciado Damião de Góis à Inquisição.

A estrutura destes dois dramas assenta em vários "quadros", que se vão cronologicamente sucedendo, e que, devido à frequente mudança, quer de cenário quer de constelações de personagens, favorecem a fluidez da própria acção. Ora estamos em Antuérpia, em casa de Baltasar de Montemor, ora estamos em Lisboa, na loja do mercador, nas arcadas do Terreiro do Paço ou na própria Torre de Belém. 0 mesmo acontece com as personagens que têm entre si, equilibradamente distribuidas, as intervenções verbais, denotando esta organização textual um grande sentido de quem está a escrever para o palco, e não para a gaveta. Neste sentido, são introduzidos, com a maior naturalidade, momentos de humor, como é o caso do diálogo travado entre Bernardim e uma "meretriz", que sugestivamente se apresenta como Felícia do Rego (cf. pp. 66-7).

Este primeiro texto dramático termina com uma interpelação directa aos espectadores, agora "hipotéticos circunstantes da época", que, pretensamente, vão usufruir dos serviços de Bernardim. Em tom irónico, o ex-candidato ao lugar de Reitor denuncia a sua situação, através da qual vislumbramos a situação do próprio país: "É esta a minha maneira de servir Portugal!, escrevendo cartas, petições, requerimentos!, nas arcadas do Terreiro do Paço!, depois de haver concluído os meus estudos no famoso Colégio de Santa Bárbara, de Paris!" (p. 81).

Quando se inicia acção de Os deserdados da pátria, passaram já dois anos e encontramo-nos em Antuérpia. 0 conjunto de personagens que por aqui passa pertence a um mesmo universo, no que diz respeito à problemática em causa: todas são, de uma forma directa ou indirecta, vítimas do estabelecimento da Inquisição. Aliás, no que toca à organização do elenco de personagens, em termos de forças em confronto, verificam-se dois grupos, de peso desigual, se considerarmos os respectivos posicionamentos ideológicos.
Temos, por um lado, D. Fradique Alvarenga e o Padre Simão Rodrigues, defensores dos processos inquisitoriais, $\mathrm{e}_{\text {, }}$ por outro, as restantes personagens, todas elas declaradamente contra esse regime de opressão. Como constata a personagem Bernardim: "Parece alastrar-se um execrável espírito de vingança, que leva muitos a denunciar inimigos ou pessoas com quem simplesmente não simpatizam. Outros, levados por um cego fanatismo religioso, não hesitam em indiciar à Inquisição os próprios parentes e amigos" (p. 152). Por outro lado, a divisão um pouco maniqueista deste universo quinhentista não poupa, até pelo ridículo, as duas personagens sobre as quais recai todo o odioso da situação: D. Fradique e o Padre Simão (cf. pp. 126-7).

Lisboa é o local onde assistimos a uma das cenas mais significativas desta segunda obra. Trata-se do encontro entre os futuros Inquisidores e um Judeu, proprietário de uma loja de quadros. Procurando peças de arte para ornamentar as salas do Colégio de Santo Antão, o Padre Simão e D. Fradique Alvarenga apreciam o triptico de Bosch que o judeu possui na loja e que, com um truque de encenação, se propõe que apareça projectado em transparência, simulando, em cena, a presença do próprio quadro.

Esta mesma imagem - As tentações de Santo Antão Santo que, nas palavras do Padre Simão, "tudo venceu com orações e penitências", volta a ter um lugar de destaque no epílogo, cujo ambiente, em didascália, se indica como sendo "quase onírico" e para onde, "por mera convenção teatral", o autor faz confluir personagens que se encontram em locais e tempos diferentes, abreviando assim o desenlace: Catarina e Bernardim, "deserdados da Pátria", navegam em busca de uma ilha deserta, onde finalmente possam encontrar paz; Damião de Góis, dispensado agora do lugar de preceptor do príncipe, permanece numa pátria que o não entende, nem aceita; e a dupla D. Fradique Alvarenga/Padre Jesuíta que, assumindo a forma dos monstros saídos do quadro de Bosch, continua a "santa cruzada da Santa Inquisição".

Eis-nos chegados ao fim da dramatização de uma situação, sobretudo assente na memória histórica. Aqui, as pessoas, individuos que foram reais, passaram a um plano de personagens construídas e tudo se consubstanciou em situações dramáticas, próximas dos acontecimentos tidos por históricos, mas sobretudo significativas no quadro de referências criado. Este sublinha o facto de, seis anos volvidos sobre o início da acção, Portugal ter mudado radicalmente o seu rumo. De país progressista, passou a um "apertado e sinistro cantinho da Europa", onde se vigia e se pune qualquer discordância de cariz religioso.

Foi este o momento do nosso passado que Norberto Ávila decidiu trabalhar e recriar, constituindo estes textos, não uma visão derrotista da História, mas antes um hino à liberdade e ao progresso, e que bem merecem ver as luzes do palco. Aproveitemos então a proposta do autor: "E se as duas peças fossem representadas em dias alternados? Experiência fascinante, sem dúvida. Para os magros tempos que vão correndo, quanto não pouparia o teatro em guardaroupa e cenografia?" (p. 5). 